\title{
Nita's revenge
}

Society. Neither was aware of any specific guidelines and directed us to the GMC's advice on patient confidentiality, for general principles. The GMC have provided some helpful recommendations, ${ }^{1}$ suggesting that provision of medical care to people with which you have a close personal relationship should be avoided. However, there do not appear to be any specific guidelines regarding employing patients as staff in general practice.

We felt it was important to raise awareness of this issue. It is clear from a number of conversations that we have had with colleagues that the practice of employing patients as staff is still widespread with all its associated problems. It would therefore make sense to prevent these situations from happening if at all possible. The geographical issue is an important one. While it may be easy for a future employee to register with a different practice around the corner if you live in an urban setting, this may be much harder to do in a rural setting. Nevertheless it is important to try to prevent boundary issues if possible. We have made a number of recommendations that could avoid such issues (Box 1), and we hope they will generate a greater awareness and further discussion.

\section{Kate Salmon and Marinus Klijnsma}

\section{REFERENCE}

1. General Medical Council. Good medical practice. Manchester: GMC, 2006. http://www.gmcuk.org/guidance/good_medical_practice/GMC_GMP .pdf (accessed 8 Dec 2008)

DOI: 10.3399/bjgp09X394932
I popped into Lily's bar for my sun downer. My friend Ben, artist and strandloper resplendent in his beaded Pondo jacket and red bandana, was looking a bit shook up - not his usual diffident persona. As we gazed at the Indian Ocean surf-line, ginpink tinted in the fading light, his voice rasped 'I almost died yesterday'. 'Tell me about it', I said thinking about maybe how he could have fallen off the steep path to his forge above the cliff, having yet again consumed too much red wine. "I saw this mushroom, about 8 inches wide on a bank near my place. I gingerly recovered it and put it in the pan. It was the most delicious mushroom that I ever tasted. About 30 minutes later, I was troubled at both ends, spewing out. I saw my neighbours as if going to work in the wrong direction when in fact they were returning homewards. I went into a deep sleep and work up in the darkest night.'

'I checked out the mushroom today - in fact it was Amanita pantherina, one of the death cup family. The last ones I saw here were about 20 years ago - that's why I didn't examine the mushroom carefully. I definitely didn't hallucinate. You know that the bog men used to give their human sacrificial offerings Amanita pantherina and the Incas gave them peyote before dispatching them. They went to their fates, grinning - on a happy trip to perdition. The other variety is used as the fly agarics. You take a piece of mushroom in a bowl of milk and the flies congregate and die. There's a volcano of them after a while.' We filled our glasses again with red wine, toasted his recovery, and trusted that it would detoxify his system of phallotoxin, even if the evidence for efficacy was lacking.

I recalled a medical genius who had to figure out, during the Second World War, why there was an epidemic of a mysterious illness in an infantry division in Poland. Men were being violently ill and out of action for a couple of weeks. Being an epidemiologist, he made a list of time, place, and personal characteristics. No common pattern emerged. He then called for a list of names of those affected. They were practically all Italian. Quickly excluding all infectious and familial syndromes, he deduced that it may be dietary. Inspiration - they could all like mushroom in the autumn. End of outbreak.

We proceeded to debate the merits of having to ingest substances to enter the mysteries of other cultures. Robert Pirsig in Lila: an inquiry into Morals, ${ }^{1}$ argued one needed to ingest peyote to truly understand the religiosity of Native American culture. We decided that imbibing alcohol was sufficient for Western and Pondo culture. We toasted James Joyce and Dylan Thomas for their cultural use of whiskey and porter. I gave a rendition of Finnegans Wake. We decided on a party list to include our aforementioned western idols and their characters of Timothy Danaos and Dona Ferentes with food cooked by Nita Phalloides. I made a mental note to politely decline vegetarian meals by artists. However, I'm still open to artistic meals by vegetarians.

\section{Don O'Mahony}

\section{REFERENCE}

1. Pirsig R. Lila: An Inquiry into Morals. New York: Bantam Books, 1991.

DOI: 10.3399/bjgp09X394941 